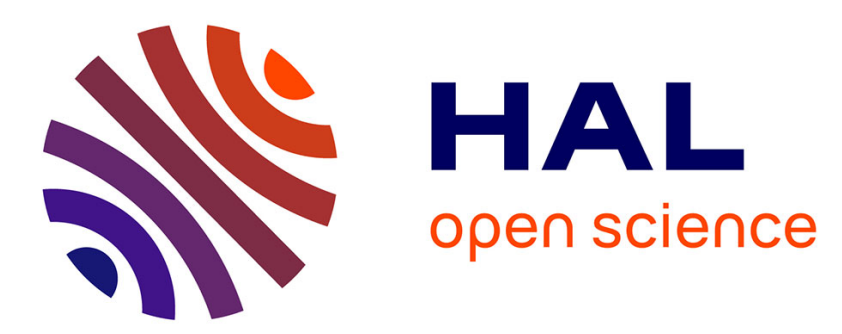

\title{
Sustainable growth and financial markets in a natural resource-rich country \\ Emma Hooper
}

\section{To cite this version:}

Emma Hooper. Sustainable growth and financial markets in a natural resource-rich country. Structural Change and Economic Dynamics, 2019, 51, pp.341-348. 10.1016/j.strueco.2018.11.007 . hal02428952

\section{HAL Id: hal-02428952 \\ https://hal-amu.archives-ouvertes.fr/hal-02428952}

Submitted on 21 Dec 2021

HAL is a multi-disciplinary open access archive for the deposit and dissemination of scientific research documents, whether they are published or not. The documents may come from teaching and research institutions in France or abroad, or from public or private research centers.
L'archive ouverte pluridisciplinaire HAL, est destinée au dépôt et à la diffusion de documents scientifiques de niveau recherche, publiés ou non, émanant des établissements d'enseignement et de recherche français ou étrangers, des laboratoires publics ou privés.

\section{다)(1) $(5$}

Distributed under a Creative Commons Attribution - NonCommercial| 4.0 International 
Version of Record: https://www.sciencedirect.com/science/article/pii/S0954349X17302904

Manuscript_716ebe8136675a04024237e7af8d7b9e

\title{
Sustainable growth and financial markets in a natural
}

\author{
resource-rich country *
}

\author{
Emma Hooper ${ }^{\dagger}$
}

October 9, 2018

\begin{abstract}
This paper studies the optimal growth path of a natural resource-rich country, which can borrow from international financial markets. I explore to what extent international borrowing can overcome resource scarcity in a small open economy, in order to have sustainable growth. First, a benchmark model with a constant interest rate and technical progress is set up to see if the economy's growth can be sustainable in the long run. Secondly, the case of a debt elastic interest rate is analysed. The main finding of this paper is that borrowing on international capital markets does not permit sustainable growth for a country with exhaustible natural resources, when the interest rate is constant. Nevertheless, when the interest rate is endogenized, the consumption growth rate can be positive before declining.
\end{abstract}

Key words: Exhaustible natural resources, exogenous growth, financial markets

JEL Classification: E20, O40, Q32, E44

*I thank Raouf Boucekkine and Patrick Pintus from Aix-Marseille School of Economics for their helpful comments, Katheline Schubert and Fanny Henriet from the Environmental Economics Lunch Seminar at the Paris School of Economics, Robert Cairns and Ngo Van Long from McGill University in Montreal, as well as Charles Seguin and Pierre Lasserre from UQAM. I am also grateful for helpful suggestions by participants of the 2015 Conference of the European Association of Environmental and Resource Economists (EAERE) at Helsinki and of the French Association of Environmental and Resource Economists (FAERE) in Toulouse, as well as those present at the 2015 International Energy Workshop (IEW) in Abu Dhabi and at the Annual Meeting of the Association of Southern European Economic Theorists (ASSET) in Granada, Spain. I would like to thank Rick van der Ploeg from the Oxford Centre for the Analysis of Resource Rich Economies (OxCarre).

${ }^{\dagger}$ Aix-Marseille University (Aix-Marseille School of Economics), CNRS, \& EHESS 


\section{Introduction}

Surprisingly, oil or gas producers, even though they have important revenues due to their natural resources, are usually facing high level of debt. For instance, Angola, which is one of the first oil producer of Africa has to deal with an external debt of 36 billion of US dollar, and Brazil had a debt of 340 billion of US dollar in 2015. Nevertheless, the issue of external debt in natural resource-rich countries has been neglected by economists so far.

In this paper, I develop one of the first analysis on this critical issue, investigating whether a natural resource dependent country with an external debt can achieve sustainable output and consumption growth rates, thanks to its access to international financial markets. The paper introduces international borrowing in an optimal exogenous growth model, with exhaustible natural resources, in which the country can borrow money at a constant interest rate and then at an endogenous interest rate. It is a one-sector model, in which the economy extracts and produces natural resources, that it can sell on the domestic market or export abroad. The choice was made not to explore a two-sector model, in order to focus on financial opening and not on trade opening. The main finding of the paper is that sustainability is not feasible when the interest rate is constant, even if there is technical progress, but when the economy faces a debt-elastic interest rate, consumption can grow for a while before decreasing in the long run.

This paper is at the crossroads of two literatures and fills important gaps in each literature. The first stream of literature deals with sustainable growth with natural resources. The cornerstone of those studies is Stiglitz's (1974) neoclassical optimal growth model, where natural resources are essential for production. He points out that optimal growth and a sustainable per capita consumption is feasible with exhaustible natural resource in limited supply, if the ratio of the rate of technical change to the the rate of population growth is greater than or equal to the share of natural resources. Solow (1974) also uses a neoclassical growth model, where he applies the max-min principle to the intergenerational 
problem of optimal capital accumulation, in general and then in particular with scarce natural resources. Dasgupta and Heal (1974) have a different approach of technical change, they do not view it as a smooth gradual process, but as technological breakthrough. They thus introduce a "backstop technology", which represents a major discovery, a new substitute for the depletable resource. An example might be the substitution of fossil fuel energy by solar or wind energy. It should be emphasized that this date of discovering is completely unknown. Nevertheless, this substitution process is a way to overcome resource scarcity and avoid a falling level of per capita consumption. Dasgupta and Stiglitz (1976) and Heal (1978) follow this approach. More recently, Benchekroun and Withagen (2011) show that in a Dasgupta-Heal-Solow-Stiglitz based model, the initial consumption under a utilitarian criterion starts below the maximin rate of consumption if and only the resource is abundant enough. They underline the fact that the present generation does not necessarily benefits most from a windfall of resources. My paper contributes to this Dasgupta-Heal-StiglitzSolow (DHSS) literature by "opening" the economy. Indeed, in most of DHSS models, those natural resource rich economies are closed, and the country does not have access to debt. As a matter of fact, very few studies examine optimal exogenous growth models with resource extraction in an open economy. There are some exceptions, as Poelhekke and Van der Ploeg (2008), Van der Ploeg and Venables (2011) who have introduced international finance in their models of resource-rich countries, which focus more on managing resource windfalls. In addition, some articles decided to introduce endogenous growth with non renewable natural resources in this literature, as Schou (1996). In particular, Barbier (1999) proposed a "Romer-Stiglitz" model, where endogenous technical change can overcome resource scarcity. Furthermore, Grimaud and Rougé (2003) analyses the effect of intervention instruments on the rate of resource extraction and growth rate in a Schumpeterian model. In this paper, I focus on an exogenous technological progress that delays the depletion of natural resources, as the main idea is to see if a resource dependent economy can have a sustainable growth rate thanks to international borrowing, while its main source of growth 
is bound to disappear. It is interesting to note that in my model technical change does not help overcome resource scarcity, contrary to Stiglitz (1974) and the rest of this literature. Indeed, consumption, investment and production asymptotically approach zero with the depletion of natural resources, despite the existence of technical change, whereas Stiglitz (1974) shows that consumption growth can be sustained thanks to technical change (at the condition that the ratio of the rate of technical change to population growth rate is higher or equal than the share of natural resources in production).

The second body of literature embraces extensions of the Ramsey model to an open economy. It is shown that the open economy version of the Ramsey model leads to a number of paradoxical conclusions. Barro and Sala-i-Martin (2003) find that the speed of convergence for capital and output is infinite, so the economy jumps into the steady state. Moreover, consumption tends to zero, except for the most patient country. Nevertheless, SchmittGrohe and Uribe (2003) display that there are different alternatives to modify the standard small open economy model. Indeed, some attempts have been made to improve those counterfactual results, by introducing a constraint on international credit or adjustment costs. The infinite speed of convergence for capital and output does not apply to countries that are effectively constrained to borrow, and consumption does not decrease to zero. With adjustment costs for investments, capital and output are less instantaneous, even if capital markets are perfect. Oxborrow and Turnovsky (2015) chose an other approach to close the small open economy model, by replacing the infinitely-lived representative agent framework with a general demographic structure, assuming a survival function, which enables them to relax the knife-edge constraint. My paper fills the gap in this small open economy literature by adding exhaustible natural resources. The resources here are essential for production, non renewable, and can apply to oil, gas, shale gas or to different minerals as copper, gold, diamonds.

In the next section, I set forth a general Ramsey model in a small open economy, with exhaustible natural resources. In section 3 , I focus on a particular case where the interest 
rate $\mathrm{r}$ is constant and with a resource-augmenting technical progress, that helps raise the efficiency of resource use. In section 4, the model is generalized with an interest rate, which is increasing in the level of debt.

\section{Theoretical framework}

A simple neoclassical growth model with natural resources is considered. It is a small open economy with borrowing capacities.

Output is produced with a constant-returns-to-scale technology, using a Cobb-Douglas production function:

$$
Y=F(K, R)=K^{\alpha}(A(1-\gamma) R)^{1-\alpha}, 0<\alpha<1
$$

where $\mathrm{K}$ is the stock of man-made capital, $\mathrm{R}$ a non renewable natural resource, $\gamma$ the share of the country's natural resources that are exported abroad, A the resource-saving technological change. A is growing at some constant exogenous rate $\tau>0$, so that $A=e^{\tau t}$. Labor is supposed to be constant, its size is thus normalized to one.

The marginal productivity of natural resources is noted as : $F^{\prime}(R)=F_{R}$. The marginal productivity of capital is defined as : $F^{\prime}(K)=F_{K}>0$ and $F^{\prime \prime}(K)<0$.

I is the investment function, s the saving function, and $\mathrm{i}$ the financial contribution, that the government can use, when the production of natural resource is low. $I=s+i=$ $Y-C+i$. The non-negativity constraint on $i$ can enable the country to rely on this financial contribution in difficult economic times, or when a large part of its natural resources will have been depleted.

The man-made capital depreciates at rate $\delta$ :

$$
\dot{K}=I-\delta K=Y-C+i-\delta K, \delta \in[0,1]
$$




\section{$2.1 \quad$ Natural resources}

Let $\mathrm{S}$ be the stock of non-renewable resources available. The economy has an initial stock of natural resources noted $\mathrm{S}(0)$.

The stock decreases over time with the rate of extraction:

$$
\dot{S}=-R
$$

with R a continuous function of time, $K(0)>0$ and $S(0)>0$.

\subsection{The government}

The economy is centralized and administered by the government, which controls the management of natural resources through a monopoly. The government has constant relative risk aversion preferences. The intertemporal utility function is:

$$
\int_{0}^{\infty} e^{-\rho t} U(C) \mathrm{d} t
$$

with $\mathrm{U}(\mathrm{C})=\frac{C^{1-\eta}-1}{1-\eta}$ for $\eta \neq 1, \eta>0$

and $\mathrm{U}(\mathrm{C})=\ln (\mathrm{C})$ for $\eta=1$

The variable $\mathrm{C}$ denotes consumption, and $\eta$ is the coefficient of relative risk aversion. The discount rate $\rho$ is assumed to be strictly positive.

The government has access to international capital markets, and can borrow or lend at an interest rate $\mathrm{r}$, which is exogenous and which depends on the level of the country's debt B. One part of the country's resources $\gamma \mathrm{R}$ is exported abroad, and the rest $(1-\gamma) \mathrm{R}$ is sold on the domestic market. 
The government's dynamic budget constraint is:

$$
\dot{B}=C+r(B) B+I-Y-\gamma p R=r(B) B+i-\gamma p R
$$

where $\mathrm{p}$ is the price of the natural resources sold abroad, and thus $\gamma p R$ is the natural resources revenue received by the government from exports.

The government maximises its lifetime utility on an infinite horizon, subject to the capital accumulation equation (2), to the natural resources stock constraint equation (3) and the budget constraint equation (5).

The problem to be solved is thus:

$$
\max _{\{C, I, R\}} \int_{0}^{\infty} e^{-\rho t} U(C) \mathrm{d} t
$$

s.t.

$$
\begin{gathered}
\dot{K}=I-\delta K \\
\dot{S}=-R \\
\dot{B}=C+r(B) B+I-Y-\gamma p R \\
K(0)>0, S(0)>0
\end{gathered}
$$

There are three state variables $\mathrm{S}, \mathrm{B}$, and $\mathrm{K}$. Three control variables $\mathrm{C}$, I and $\mathrm{R}$ to be chosen.

The current value Hamiltonian is :

$\mathrm{H}\left(\mathrm{C}, \mathrm{R}, \mathrm{I}, \lambda_{1}, \lambda_{2}, \lambda_{3}\right)=\mathrm{U}(\mathrm{C})+\lambda_{1}(I-\delta K)-\lambda_{2} R+\lambda_{3}(C+r(B) B+I-Y-\gamma p R)$

The co-states $\lambda_{1}, \lambda_{2}, \lambda_{3}$ represent respectively the shadow price of accumulated capital, of the resource stock and the shadow price of debt.

The optimality conditions are given by: 


$$
\begin{gathered}
U^{\prime}(C)=-\lambda_{3} \\
-\lambda_{3}\left(F_{R}+\gamma p\right)=\lambda_{2} \\
-\lambda_{3}=\lambda_{1} \\
\dot{\lambda_{1}}=\lambda_{1}(\delta+\rho)+\lambda_{3} F_{K} \\
\dot{\lambda_{2}}=\rho \lambda_{2} \\
\dot{\lambda_{3}}=\lambda_{3}\left(\rho-r^{\prime}(B) B+r(B)\right)
\end{gathered}
$$

At the optimum rate, the rate of return is the same at all points in time, being equal to the social discount rate (equation 10): $\frac{\dot{\lambda}_{2}}{\lambda_{2}}=\rho$

As the Hotelling rule goes, the shadow price of the resource in the ground, also called the scarcity rent, grows at the discount rate.

The transversality conditions are:

$$
\begin{aligned}
& \lim _{t \rightarrow \infty} e^{-\rho t} \lambda_{1} K=0 \\
& \lim _{t \rightarrow \infty} e^{-\rho t} \lambda_{2} S=0 \\
& \lim _{t \rightarrow \infty} e^{-\rho t} \lambda_{3} B=0
\end{aligned}
$$

It is not possible to accumulate capital and debt indefinitely. As in the long run, the natural resource will be exhausted, the country cannot extract those resources indefinitely. 


\section{Model with a constant interest rate and technical progress}

In the literature of sustainable growth with natural resources in a closed economy, such as Stiglitz (1974) or Dasgupta and Heal (1974), sustainability is not feasible without technical progress. Without public debt in my model, the country cannot rely on international borrowing and depends completely on its natural resources, that are essential for production. In this case of a closed economy, growth is not sustainable in the long run, as those natural resource are non renewable and no technical progress can help overcome the resource scarcity. On the contrary, when financial openness is introduced in my model, the economy can tap financial markets, and can find a new way to support consumption. Nevertheless, despite this access to international markets my results (without technical change) are similar to those of the literature of optimal growth models with natural resource in a closed economy. Therefore, in a small open economy producing exhaustible natural resources, with a constant interest rate and no technical progress, all the variables output, capital, consumption, natural resources, the level of debt grow at the same rate along a balanced growth path and decline asymptotically towards zero (see Appendix 1).

I now consider a resource-augmenting technical progress in the model to see if the country can reach a sustainable growth path. This assumption can be supported by the fact that technological change can lead to the discovery of new natural resources (like the discovery of oil fields in Brazil), or allow the exploitation of resources previously thought not to be economically accessible (as offshore high pressure - high temperature wells for example). Different types of technical changes have been developed in the literature. Technical change can be seen as a gradual process, or like a major discovery. Dasgupta and Heal (1974) view it like a backstop technology that can appear at a discrete time. Endogenous technical change have also been introduced in the literature, especially by Grimaud and Rougé (2003), Lafforgue (2008). This paper focuses on an exogenous technical change, which can delay 
the depletion of natural resources but which is not a substitute to those resources.

Furthermore, the economy has unrestricted access to a perfect world capital market. It is assumed that the interest rate equals a constant $\mathrm{r}$ and that $\mathrm{r} \leq \rho$ applies, because if not the economy would eventually accumulate enough assets to violate the small-country assumption that we made (Barro and Sala-i-Martin, 2003). This condition is justified by the fact that small natural resource-rich economies usually exhibit high discount rates. Indeed, as an example Adelman (1986) shows that oil-producing countries that heavily depend on oil revenues have a higher discount rate than a diversified economy. Revenues generated from exhaustible natural resources are highly dependent on resource price fluctuations, contrary to more diversified economies that can rely on other sources of revenues. For example, Saudi Arabia's discount rate is higher than Kuwait's discount rate, as Kuwait has some non-oil income derived from foreign investment. Another justification supporting this central assumption is that natural resource-rich countries are usually more subject to high political instability. For example, Nigeria or Venezuela have high discount rates (which are thus higher than the interest rate), since they can face many coups. If the government knows he can be overthrown by its political opponents at any moment, its preference for the present is even higher. Indeed, he ought to produce more now in order to keep itself in power by buying off potential rivals (Easterly, 2002). For those reasons, governments in natural resource-rich countries can thus calculate with short-horizon and high discount rate.

In this model, prices and the interest rate are assumed to be constant. Natural resource prices are usually set on a world market, as it is the case for oil, or at a more regional level like gas. Moreover, governments in small open economies do not have the power to influence the resource price, that is crucial for their revenues. The analysis is conducted with a constant resource price.

The marginal productivity of capital and the marginal productivity of the resource can be expressed as: 


$$
\begin{gathered}
F_{K}=\alpha\left(\frac{K}{A(1-\gamma) R}\right)^{\alpha-1} \\
F_{R}=(1-\alpha)\left(\frac{K}{A(1-\gamma) R}\right)^{\alpha} A(1-\gamma)
\end{gathered}
$$

Using (8) and (11) yields that the marginal productivity of capital is equal to the depreciation rate plus the interest rate:

$$
F_{K}=\delta+r
$$

This implies that the ratio $\frac{K}{A(1-\gamma) R}$ is constant:

$$
\frac{K}{A(1-\gamma) R}=\left(\frac{\delta+r}{\alpha}\right)^{\frac{1}{\alpha-1}}
$$

As natural resources are exhaustible, therefore the rate of extraction of those resources tends towards zero. Since the ratio $\frac{K}{A(1-\gamma) R}$ is constant, this implies that the accumulation of capital approaches zero. And as the production function is a Cobb-Douglas, therefore output also decreases towards zero. Those results appear to be quite counterfactual, as the economy can no longer grow in the long run.

Moreover, the modified Solow-Stiglitz efficiency condition holds:

$$
\frac{F_{R} \dot{+} \gamma p}{F_{R}+\gamma p}=F_{K}-\delta=r
$$

In other words, along the optimal path the interest rate has to be equal to the growth rate of the marginal productivity of the resource plus the government's revenue of exported resources.

Using this last efficiency condition and as the ratio $\frac{K}{A(1-\gamma) R}$ is constant, therefore its 
growth rate $g_{\frac{K}{A(1-\gamma) R}}=\frac{\frac{\dot{K}}{A(1-\gamma) R}}{\frac{K}{A(1-\gamma) R}}$ is equal to zero, it yields :

$$
\begin{gathered}
\frac{\dot{F_{R}}}{F_{R}}=\alpha\left(\frac{\frac{\dot{K}}{A(1-\gamma) R}}{\bar{A}(1-\gamma) R}\right)+\frac{\dot{A}}{A} \\
\dot{F_{R}}=\frac{\dot{A}}{A} F_{R}
\end{gathered}
$$

This equation can thus be reexpressed as:

$$
\frac{F_{R} \dot{+} \gamma p}{F_{R}+\gamma p}=\frac{\tau F_{R}}{(1-\alpha)(1-\gamma)\left(\frac{K}{A(1-\gamma) R}\right)^{\alpha} A+\gamma p}
$$

Proposition 1: The optimal growth rate of consumption is given by:

$$
g_{C}=\frac{\dot{C}}{C}=\frac{r-\rho}{\eta}
$$

and along a balanced growth path, $g_{Y}=g_{K}=g_{I}=g_{C}$ and $g_{R}<0$

Concerning consumption growth, this is straightforward from equations (6) and (11), which give the Keynes-Ramsey rule. Therefore, the consumption growth rate is negative, as $r \leq \rho$. Consumption cannot be sustainable in the long run. This result confirms what has been shown in the literature extending the Ramsey model to an open economy by allowing for international borrowing, where consumption also tended to zero in impatient economies (Barro and Sala-i-Martin, 2003). Nevertheless, this result is different from Stiglitz (1974), where thanks to technical progress there is sustainability in a closed economy with exhaustible natural resources, if the ratio of the rate of technical change to population growth rate is higher or equal than the share of natural resource in production. Therefore, in my model, consumption declines despite an access to financial markets and technical change. 
This is quite counterfactual, as natural resource-rich countries, that start producing their resources, usually have high level of consumption. Indeed, consumption increases at first thanks to those new resource flows, and then decreases with the resource depletion, especially if the country did not diversify its economy through structural reforms, or if it has been plagued by rent seeking instead of investing. Moreover, creditors are usually willing to lend to those natural resource-rich countries, as they know they will have new revenues stemming from those resources. That has been the case of many developing countries, which have been able to borrow on financial markets thanks to their oil discoveries. For example, Ecuador had a larger access to international borrowing in the 1970's when it started to produce and export oil. Stylized facts show that financial openness can thus be an opportunity to increase the country's consumption, contrary to my model with a constant interest rate.

Moreover, a balanced growth path (BGP) is defined as a path along which the quantities $\mathrm{Y}, \mathrm{C}$ and $\mathrm{K}$ change at constant proportionate rates. Let $g_{x}$ denote the growth rate of the variable $x>0$, that is $g_{x}=\frac{\dot{x}}{x}$.

As the ratio $\frac{K}{A(1-\gamma) R}$ is constant, by differenciating logarithmically:

$$
g_{\frac{K}{A(1-\gamma) R}}=g_{K}-g_{A(1-\gamma) R}=0
$$

and $g_{A(1-\gamma) R}=g_{A}+g_{(1-\gamma) R}=g_{A}+g_{R}$, as $\gamma$ constant

This implies that:

$$
g_{K}=g_{A}+g_{R}
$$

Furthermore, as $g_{K}=g_{C}$, we have: $g_{R}=g_{C}-g_{A}$

Then,

$$
g_{R}=\frac{r-\rho}{\eta}-\tau
$$

Therefore $g_{R}<0$, as $\tau>0$ and $\mathrm{r} \leq \rho$. 
The pace of the natural resource extraction is decreasing with time. In the long-term, the natural resource is being extracted until it is depleted, even though there will still be some resource left in the ground. Indeed $\mathrm{R}$ will never be completely equal to zero, but will asymptotically approach zero.

Concerning the debt path, as output, investment and natural resources, it tends asymptotically towards zero. Indeed, by considering the budget constraint and the transversality conditions, it leads to $\lim _{t \rightarrow+\infty} B(t)=0$.

This implies that the maximum that the debt growth rate, noted $\operatorname{maxg}_{B}$, can reach is :

$$
\max g_{B}=\frac{r-\rho}{\eta}-r
$$

In conclusion, in a small open economy with exhaustible natural resources when there is technical progress and a constant interest rate, all the variables output, capital, consumption, natural resources, and the level of debt decline towards zero. Those results are different from Barro and Sala-i-Martin (2003), who show that extensions of a Ramsey model to an open economy do not lead to a declining output in the long term, even though consumption can be decreasing. Those results also differ from Stiglitz (1974), where optimal growth is feasible to a certain condition on technical change, despite the limited supply of natural resources. Surprisingly, in my model technical progress cannot overcome resource scarcity, as the interest rate is exogenous and constant. Extending a Ramsey model to an open-economy with natural resources, lead to counterfactual results. As natural resource revenues dwindle away, the economy ends up with a lower level of debt and a lower level of consumption in the long run. Moreover, along the BGP those variables do not grow at the same rate. Therefore, contrary to Stiglitz (1974) positive growth rates for output and consumption cannot be sustained in the long run. 


\section{Model with a debt-elastic interest rate}

The economy faces now limitations in its access to the world financial markets. It is indeed more realistic than a country that can borrow as much as it wants at a fixed rate.

The interest rate $r(B)$ depends on the level of debt. It is thus assumed that $r(B)$ is increasing in the aggregate level of foreign debt.

As in the literature it is more common to use an exponential interest rate, I refer to Schmitt-Grohe and Uribe (2003) debt-elastic interest-rate premium. It can be expressed as:

$$
r(B)=r^{*}+\psi\left(e^{B-D}-1\right)
$$

where $\psi\left(e^{B-D}-1\right)$ is the country-specific interest rate premium, $r^{*}$ is the world interest rate, $\mathrm{D}$ is the steady-state level of foreign debt. $r^{*}, \mathrm{D}$ and $\psi$ are constant and positive parameters. Therefore, when the level of debt reaches its steady-state, i.e. $B=D$, it implies that the interest rate equals the international interest rate: $r(B)=r^{*}$

Therefore the formulation of the interest rate implies $r(B)>0$ and $r^{\prime}(B)=\psi e^{B-D}>0$.

Using the optimality conditions of the general model, especially equations (8), (9) and (11), the marginal productivity of the capital depends on the interest rate:

$$
F_{K}=\delta+r^{\prime}(B) \cdot B+r(B)
$$

As $F_{K}=\alpha\left(\frac{K}{A(1-\gamma) R}\right)^{\alpha-1}$, we can find the ratio $\frac{K}{A(1-\gamma) R}$ :

$\frac{K}{A(1-\gamma) R}=\left(\frac{\delta+r^{\prime}(B) \cdot B+r(B)}{\alpha}\right)^{\frac{1}{\alpha-1}}=\left(\frac{\psi e^{B-D} \cdot B+r^{*}+\psi\left(e^{B-D}-1\right)+\delta}{\alpha}\right)^{\frac{1}{\alpha-1}}$

From equations (7), (10), (11) and (17), the marginal productivity of the natural re- 
Figure 1: Exponential interest rate $\mathrm{r}(\mathrm{B})$ in function of the level of debt

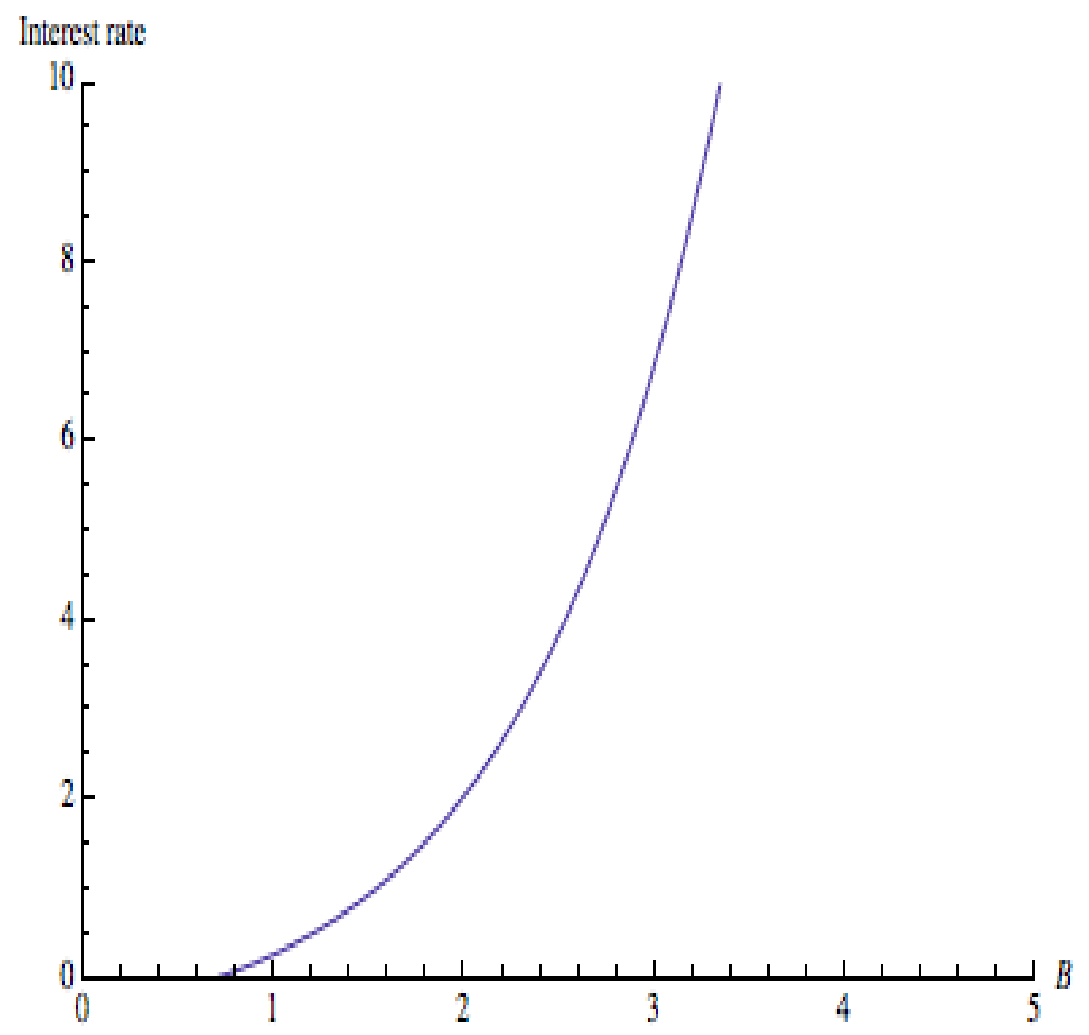

sources is given by:

$$
\frac{F_{R} \dot{+} \gamma p}{F_{R}+\gamma p}=F_{K}-\delta=r^{\prime}(B) \cdot B+r(B)
$$

This relation corresponds to the new Solow-Stiglitz efficiency condition in an open economy with a debt-elastic interest rate.

Proposition 2: The optimal level of debt decreases and output falls to zero in the long run.

This is quite a paradoxical result, as the economic policy recommended here is to pay off its debt from the beginning and thus not to take any risks. The economic intuition is 
to avoid debt-overhang. Indeed, as resource flows will not continue indefinitely, the country should avoid excessive borrowing.

Allowing for international borrowing should help the economy limit its dependence on those resources, through the diversification of its economy (by developing tourism, like in Indonesia). Nevertheless, it should avoid getting trapped in a debt spiral and try to pay back its debt while it still receive revenues from its natural resource. Furthermore, as this resource is exhaustible, the challenge is to save money for future generations (by creating a sovereign wealth fund for example), and thus not to spend all those revenues in the present. Indeed, if the country just borrows on financial markets in order to maintain its consumption to a certain level and does not use this financial openness as a mean to diversify its economy, the country will accumulate too much debt. Investors will not be willing to lend to this country, whose main source of revenue (its natural resources) is bound to disappear. A mismanagement of debt and natural resources can thus lead to difficult economic consequences, as it is currently the case in Venezuela, which is strangled by its debt even though it has huge oil reserves.

A numerical example is provided to illustrate the debt pattern in function of time when the interest rate is exponential (Figure 2). More precisely, I set $\alpha=0,32, \delta=0,1, p=1$, $\gamma=0,5, r *=0,04, D=0,7442$ and $\psi=0,8$, and plot the optimal debt path in function of time.

According to (18) and as the level of debt is falling to zero, the ratio $\frac{K}{A(1-\gamma) R}$ also approaches asymptotically a constant. I thus find the same counterfactual results from the benchmark model with a constant interest rate $\mathrm{r}$ concerning the accumulation of capital, the level of investment, and output that decrease asymptotically towards zero.

Proposition 3: The optimal rate of consumption is given by:

$$
\frac{\dot{C}}{C}=\frac{F_{K}-\delta-\rho}{\eta}=\frac{r^{\prime}(B) \cdot B+r(B)-\rho}{\eta}, \eta>1
$$


Figure 2: Debt path in function of time

With an exponential interest rate $r(B)$

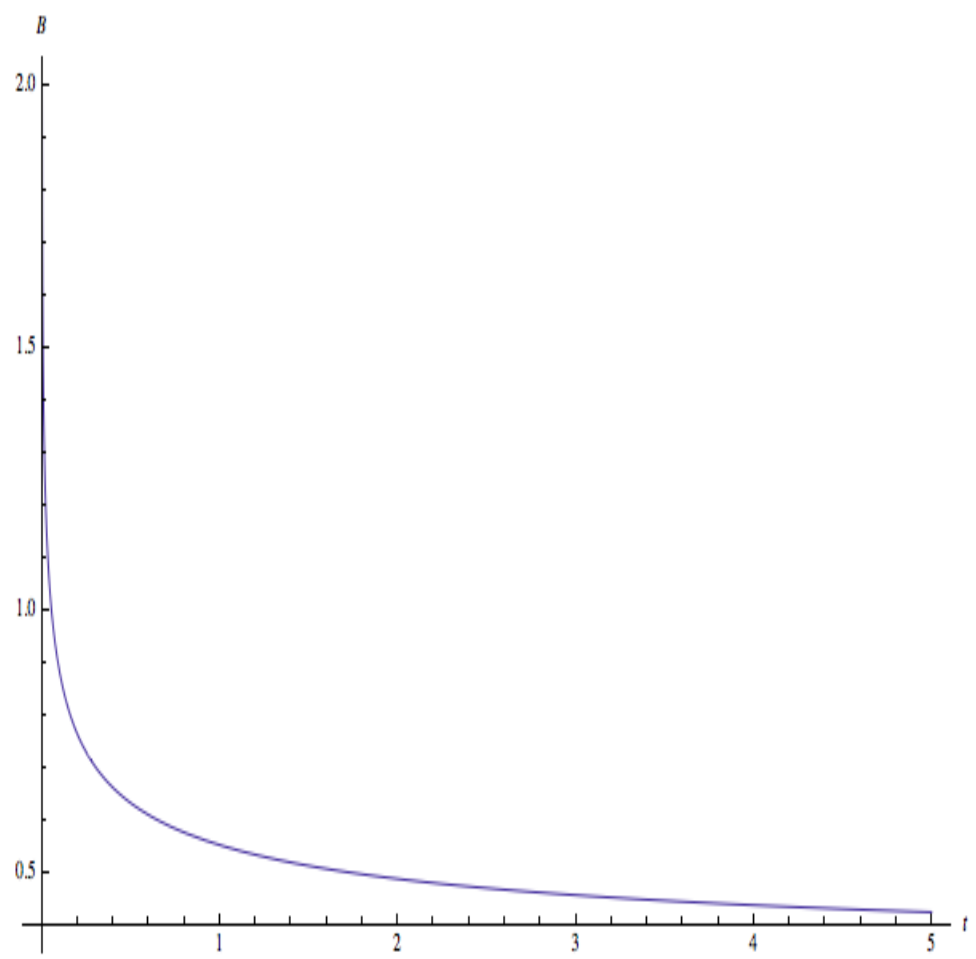

This is straightforward from equations (6) and (11). Consumption accumulates at a rate equal to the difference between the net marginal product of capital $F_{K}-\delta$ and the discount rate $\rho$.

Nevertheless, this time the consumption growth rate $g_{C}$ is depending on the level of debt $B_{t}$, contrary to the model with a constant interest rate.

In fact during the transitional dynamics, the consumption growth rate is first positive: $g_{C} \geq 0$ when $r^{\prime}(B) \cdot B+r(B) \geq \rho$. The country borrows to enjoy a certain level of consumption early on, but pays the price later in the form of low consumption growth rate. In the long run, as the level of debt B tends asymptotically towards zero, this growth rate becomes negative, thus $g_{C} \leq 0$, and consumption decreases. Those results are still different from Stiglitz (1974), as consumption is not sustainable in the long run, even though this 
time the consumption growth rate is positive at the beginning.

To illustrate the consumption growth rate in function of time when the interest rate is exponential (Figure 3), I set $\alpha=0,32, \delta=0,1, p=1, \gamma=0,5, r *=0,04, D=0,7442$ and $\psi=0,8$.

Figure 3: Consumption growth rate in function of time With an exponential interest rate $r(B)$

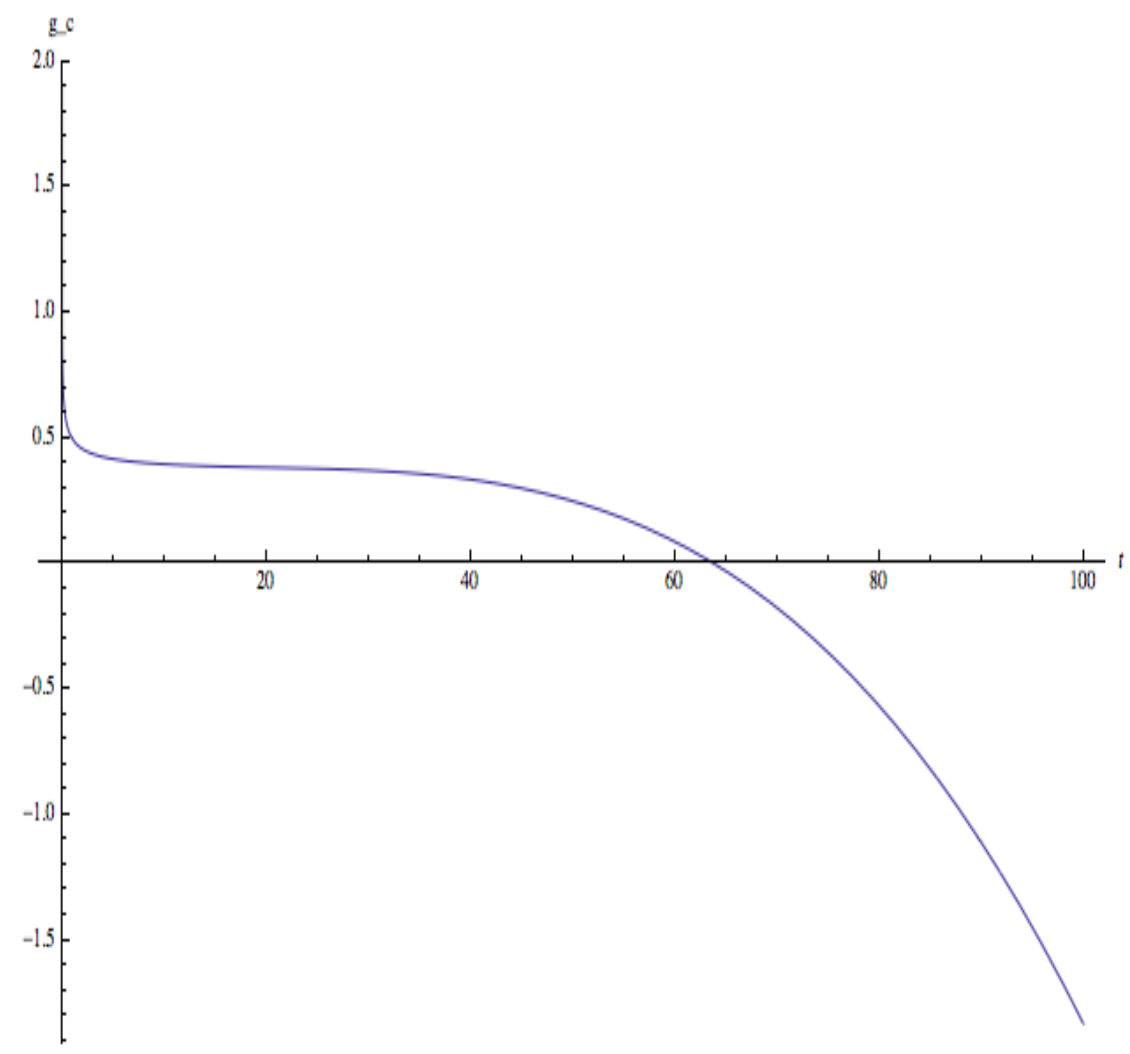

It can be seen that the consumption growth rate is first positive, and then declines in the long run. Therefore, when the interest rate is endogenized, consumption can grow for a while before decreasing. The inverted U-shape of consumption can be explained by the fact that natural resource-rich countries usually have high level of consumption when they start extracting their resources. But with the resource depletion, the country produces less 
and exports less its natural resources. It has thus less revenues and its consumption tends to decrease. That is the case of some oil producing countries, that when they start exporting oil they have high level of consumption, but with the decrease of their oil production, consumption is then declining. 


\section{Conclusion}

This paper has developed an exogenous optimal growth model of a resource-rich open economy, where natural resources are essential for production and non-renewable.

The main finding is that sustainability is not feasible when the interest rate is constant, even if there is technical progress, but when the economy faces a debt-elastic interest rate, consumption can grow for a while before decreasing in the long-run.

First, it was shown that when the interest rate is assumed constant and with technical progress, this economy is faced to decreasing consumption and production. This leads to some counterfactual no-growth results, as all the variables approach asymptotically zero and that natural resources and output, consumption do not grow at the same rate on a balanced growth path. Contrary to Stiglitz (1974), resource augmenting technical progress does not overcome resource scarcity. In the literature extending Ramsey models to an open economy, borrowing constraints with a collateral or adjustment costs are usually added in order to found less paradoxical results, but my approach is different. I introduce an interest rate that increases in the aggregate level of debt. It is a more realistic assumption, as countries usually face a risk premium. Second, when the interest rate is endogenized, the optimal level of debt asymptotically declines, and so do the output, capital and investment. Therefore, the country ought to pay back its debt. Nevertheless, the growth rate of consumption is positive during the transitional dynamics before declining. The country can thus see its consumption increase at first in the debt-elastic interest rate model, but it then decreases in the long run. In fact, neither technical change nor financial openness enable the country to sustain its consumption in the long-term in my model. To overcome resource depletion, the country should switch to an economy, where natural resources are no longer essential to production. The policy recommendation for those natural resource-rich countries is thus to reduce their debt and to diversify their economy in order to overcome resource scarcity.

This paper can be considered as a contribution to the optimal growth models with ex- 
haustible natural resources, that focused mainly on closed economies. One way to extend this paper would be to optimize the model according to $\gamma$ the share of the country's natural resources exported abroad. Another extension would be to introduce a constraint on international credit, where natural resources could be used as collateral. 


\section{References}

Adelman M.A. (1986), "Oil producing countries' discount rates", M.I.T. Enerfy Laboratory Working Paper.

Barbier, E.B. (1999), "Endogenous Growth and Natural Resource Scarcity", Environmental and Resource Economics 14: 51-74.

Barro, R. and Sala-i-Martin,X. (2003), Economic Growth, Cambridge, Mass., The MIT Press.

Benchekroun, H. and Withagen C. (2011),"The optimal depletion of exhaustible resources: A complete characterization." Resource and Energy Economics 33(3): 612 - 636 .

Dasgupta, P. and Heal, G. (1974), "The optimal depletion of exhaustible resources", Review of Economic Studies, Symposium on the Economics of Exhaustible Resources: 3-28

Easterly, W. (2002), "How did the heavily indebted poor countries become heavily indebted? Reviewing 2 decades of debt relief", World Development, 30(10): 1677-1696

Gilbert, R.J. (1979), "Optimal Depletion of an Uncertain Stock", Review of Economic Studies 46: 47-57.

Grimaud, A. and Rougé, L. (2003), "Non-renewable resources and growth with vertical innovations: optimum, equilibrium and economic policies", Journal of Environmental Economics and Management 45: 433-453.

Heal, G. (1979), "Uncertainty and the Optimal Supply Policy for an Exhaustible Resource", In Advances in the Economics of Energy and Resources.Vol. 2.

Hotelling, H. (1931), "The Economics of Exhaustible Resources", Journal of Political Economy 39: 137-175.

Loury, G. (1978)," The Optimal Exploitation of an Unknown Reserve", Review of Economic Studies $45: 621-36$.

Oxborrow, D. and Turnovsky, S. J. (2015), "Closing the Small Open Economy Model: A demographic Approach", University of Washington Working Paper. 
Poelhekke, S. and van der Ploeg, F. (2008), "Volatility, Financial Development and the Natural Resource Curse," OxCarre Working Papers 003, Oxford Centre for the Analysis of Resource Rich Economies, University of Oxford.

Schmitt-Grohe, S. and Uribe, M. (2003),"Closing small open economies", Journal of International Economics 61: 163-185.

Schou, P. (1996), "A Growth Model with Technological Progress and Non- renewable Resources", Mimeo, University of Copenhagen (1996).

Solow, R. (1974), "Intergenerational equity and exhaustible resources", Review of Economic Studies, Symposium on the Economics of Exhaustible Resources: 29-46.

Stiglitz, J. (1974), "Growth with exhaustible natural resources: Efficient and optimal growth paths", Review of Economic Studies, Symposium on the Economics of Exhaustible Resources: 123-137.

Van der Ploeg, F. and Venables, A. (2011), "Harnessing Windfall Revenues: Optimal Policies for ResourceRich Developing Economies", The Economic Journal 551:1-30 


\section{Appendix}

\section{Appendix 1 : Model with a constant interest rate and no technical progress}

The production function can be written as : $Y=F(K, R)=K^{\alpha}((1-\gamma) R)^{\alpha-1}$

With an interest rate $\mathrm{r}$ constant, the government's dynamic budget constraint is:

$$
\dot{B}(t)=C(t)+r B(t)+I(t)-Y(t)-\gamma p R(t)
$$

The optimality conditions remain the same as in the general model, except for equation (11) that becomes:

$$
\dot{\lambda_{3}}(t)=\lambda_{3}(t)(\rho-r)
$$

Using (8) and (11) yields that the marginal productivity of capital is equal to the depreciation rate plus the interest rate:

$$
F_{K}=\delta+r
$$

Besides, using the production function and equation (23), the marginal productivity of capital can be reexpressed as:

$$
F_{K}=\alpha\left(\frac{K}{(1-\gamma) R}\right)^{\alpha-1}=\delta+r
$$

It leads to a ratio capital natural resource $\frac{K}{(1-\gamma) R}$ which is constant, when the interest rate $\mathrm{r}$ is constant:

$$
\frac{K}{(1-\gamma) R}=\left(\frac{\delta+r}{\alpha}\right)^{\frac{1}{\alpha-1}}
$$

From (9) and (11), the marginal productivity of natural resources depends on the price 
of those resources and on the interest rate:

$$
F_{R}+\gamma p=-\frac{\lambda_{2}(0)}{\lambda_{3}(0)} e^{r t}
$$

As one can note, there is an incompatibility between equation (24), which grows exponentially, and the marginal productivity of the natural resources derived from the production function, $F_{R}+\gamma p=(1-\alpha)(1-\gamma)\left(\frac{K}{(1-\gamma) R}\right)^{\alpha}+\gamma p$, which is constant.

We have to distinguish two cases: - If the country does not export its natural resources, then $\gamma=0$, the model does not work. Equation (24) becomes:

$$
F_{R}=-\frac{\lambda_{2}(0)}{\lambda_{3}(0)} e^{r t}
$$

which is not possible as $F_{R}$ is constant.

- If the country exports its natural resources, equation (24) holds if and only if prices increase at a rate $\mathrm{r}$. Therefore, prices can be reexpressed as:

$$
p(t)=p(0) e^{r t}
$$

Using equations (23) and (24) boils down to a new Solow-Stiglitz condition:

$$
\frac{\dot{F_{R}}+\gamma \dot{p}}{F_{R}+\gamma p}=F_{K}-\delta=r
$$

It is shown that along the optimal path, the growth rate of the marginal productivity of the natural resources plus the growth rate of the prices have to be equal to the interest rate.

Proposition: The optimal rate of consumption is given by 


$$
g_{C}=\frac{\dot{C}}{C}=\frac{r-\rho}{\eta}, \eta>1
$$

$$
\text { If } \eta=1, \frac{\dot{C}}{C}=r-\rho
$$

Proof: This is straightforward from equations (6) and (11), which give the KeynesRamsey rule.

As $r \leq \rho$, the rate of consumption is negative, therefore consumption decreases asymptotically towards zero. This result confirms what has been shown in the literature extending the Ramsey model to an open economy with international borrowing, where consumption also tended to zero.

I shall see now what are the implications of a constant ratio capital natural resource on output.

Proposition: The optimal path of output and stock of capital approach zero.

Proof: As the natural resources are exhaustible, therefore the rate of extraction of those resources tends towards zero: $\lim _{t \rightarrow+\infty} R=0$

Since the ratio $\frac{K}{(1-\gamma) R}$ is constant, this implies that the accumulation of capital also approaches zero

$$
\lim _{t \rightarrow+\infty} K=0
$$

As $\mathrm{K}$ and $\mathrm{R}$ are falling to zero, therefore output also decreases towards zero:

$$
\lim _{t \rightarrow+\infty} Y=0
$$


In other words, not just the growth rate but even the level of output will vanish.

In addition, from equation (2), the level of investment is also approaching zero:

$$
\lim _{t \rightarrow+\infty} I=0
$$

Those no-output and no-growth results appear to be counterfactual. Especially, the fact that production also falls towards zero leads to an economy on the way to extinction.

Adding exhaustible natural resources to an open economy version of the Ramsey model leads thus to different results from those models with no natural resources, where the speed of convergence for capital and output is infinite.

A balanced growth path (BGP) is defined as a path along which the quantities $\mathrm{Y}, \mathrm{C}$ and $\mathrm{K}$ change at constant proportionate rates.

Proposition: Along a $B G P, g_{Y}=g_{K}=g_{I}=g_{C}=g_{R}$

Proof: Let reexpress the production function in growth rate, such as $g_{x}=\frac{\dot{x}}{x}$ :

$$
Y=\left(\frac{K}{(1-\gamma) R}\right)^{\alpha} R
$$

Then,

$$
g_{Y}=\alpha g_{\frac{K}{(1-\gamma) R}}+g_{R}
$$

As the ratio $\frac{K}{(1-\gamma) R}$ is constant, its growth rate equals zero.

Therefore, $g_{K}=g_{R}$ and $g_{Y}=g_{R}$ 
Then, $g_{Y}=g_{K}=g_{I}=g_{R}=g_{C}=\frac{r-\rho}{\eta} \leq 0, \eta>1$

Concerning the debt path, the budget constraint need to be considered:

$\dot{B}(t)=C(t)+r B(t)+I(t)-Y(t)-\gamma p R(t):$

$$
B(t)=b_{1} e^{r t}+b_{2} e^{\frac{r-\rho}{\eta} t}+b_{3} e^{\left(\frac{r-\rho}{\eta}+r\right) t}
$$

Solving this, with the transversality condition $\lim _{t \rightarrow \infty} e^{-\rho t} \lambda_{3}(t) B(t)=0$ and the corresponding solution $\lambda_{3}(t)=\lambda_{3}(0) e^{(\rho-r) t}$ yields:

$$
\begin{gathered}
\lim _{t \rightarrow+\infty} \lambda_{3}(0)\left(b_{1} e^{r t}+b_{2} e^{\frac{r-\rho}{\eta} t}+b_{3} e^{\left(\frac{r-\rho}{\eta}+r\right) t}\right) e^{-r t}=0 \\
\lambda_{3}(0) \lim _{t \rightarrow+\infty}\left(b_{1}+b_{2} e^{\left(\frac{r-\rho}{\eta}-r\right) t}+b_{3} e^{\frac{r-\rho}{\eta} t}\right)=0
\end{gathered}
$$

From the transversality condition, it is shown that $b_{1}=0$ and as $\mathrm{r} \leq \rho, \lim _{t \rightarrow+\infty} B(t)=$ 0 .

This induces that

$$
\operatorname{maxg}_{B}=\frac{r-\rho}{\eta}
$$

Appendix 2: Proof of $\lim _{t \rightarrow+\infty} B(t)=0$ in the model with a constant interest rate and technical progress

As in Appendix 1, concerning the debt path, the budget constraint is considered. Knowing that $\mathrm{Y}$, I and R tend asymptotically towards zero, with constant prices :

$$
B(t)=b_{1} e^{r t}+b_{2} e^{\frac{r-\rho}{\eta} t}
$$


Solving this, with the transversality condition $\lim _{t \rightarrow \infty} e^{-\rho t} \lambda_{3}(t) B(t)=0$ and the corresponding solution $\lambda_{3}(t)=\lambda_{3}(0) e^{(\rho-r) t}$ yields:

$$
\begin{gathered}
\lim _{t \rightarrow+\infty} \lambda_{3}(0)\left(b_{1} e^{r t}+b_{2} e^{\frac{r-\rho}{\eta} t}\right) e^{-r t}=0 \\
\lambda_{3}(0) \lim _{t \rightarrow+\infty}\left(b_{1}+b_{2} e^{\left(\frac{r-\rho}{\eta}-r\right) t}\right)=0
\end{gathered}
$$

From the transversality condition, it leads to $b_{1}=0$ and as $\mathrm{r} \leq \rho$, then $\lim _{t \rightarrow+\infty} B(t)=0$.

\section{Appendix 3 : Proof of Proposition 2 in the model with a debt-elastic interest} rate

Using (16) and (18), yields:

$$
\frac{F_{R} \dot{+} \gamma p}{F_{R}+\gamma p}=\frac{1}{\alpha} * G(B) \cdot r^{\prime}(B) * \dot{B}
$$

with

$$
G(B)=\alpha \frac{\frac{1}{\alpha-1}\left(r^{\prime}(B) \cdot B+r(B)+\delta\right)^{\left(\frac{1}{\alpha-1}-1\right)}}{\left.\left(r^{\prime}(B) \cdot B+r(B)+\delta\right)^{\left(\frac{1}{\alpha-1}\right.}\right)}
$$

And thus with (19), it leads to a function of B, $\mathrm{r}(\mathrm{B}), \mathrm{r}^{\prime}(\mathrm{B}), G(B)<0$ :

$$
\frac{1}{\alpha} * G(B) \cdot r^{\prime}(B) * \dot{B}=r^{\prime}(B) \cdot B+r(B)
$$

This condition can be reexpressed as the following autonomous differential equation:

$$
\dot{B}=H(B)
$$

with $H(B)=\left(r^{\prime}(B) \cdot B+r(B)\right) * \frac{\alpha}{G(B) * r^{\prime}(B)}$ 
As $B>0, r(B)>0$ and $r^{\prime}(B)>0$, and $G(B)<0, H(B)=\dot{B}$ is thus negative.

Therefore, the optimal level of debt B is decreasing with time.

\section{Appendix 4 : Model with a debt-elastic interest rate with increasing prices}

In this case, prices are no longer constant. They are now assumed to increase at a rate $\theta$, with: $p(t)=p(0) e^{\theta t}$. The idea is to see if increasing prices, like in 2002-2008 where the oil price went from $20 \$$ to $140 \$$, can help have a sustainable growth.

The equation (20) becomes:

$$
\frac{\dot{F_{R}}+\gamma \dot{p}}{F_{R}+\gamma p}=\frac{G(B) \cdot r^{\prime}(B) * \dot{B}+\gamma \dot{p}}{\alpha}
$$

$$
\frac{G(B) \cdot r^{\prime}(B) * \dot{B}+\gamma \dot{p}}{\alpha}=r^{\prime}(B) \cdot B+r(B)
$$

This condition can be reexpressed as the following non autonomous differential equation, as p depends now on time:

$$
\dot{B}=H_{2}(B)
$$

with $H_{2}(B)=\frac{\alpha\left(r^{\prime}(B) \cdot B+r(B)\right)-\gamma \dot{p}}{G(B) * r^{\prime}(B)}$

As it is known from below $r(B)>0, r^{\prime}(B)>0$, and $G(B)<0$.

Moreover, $\gamma>0$ and $\dot{p}>0$. Therefore, when $\alpha\left(r^{\prime}(B) \cdot B+r(B)\right)<\gamma \dot{p}$, then $\dot{B}>0$. Let us 
apply this condition in the case where $\mathrm{B}(0)$ takes the value of zero and when the interest rate is exponential, this condition becomes: $\alpha\left(r^{*}+\psi\left(e^{-D}-1\right)\right)<\gamma p(0)$. As $\mathrm{p}(0)$ is assumed to be equal to one, then $p(0)=\theta$. This inequality is thus verified when $\psi\left(e^{-D}-1\right)<\frac{\gamma \theta}{\alpha}-r^{*}$. In that case, the country increases its level of debt. In the short-run, it is interesting to see that as debt is growing, consumption grows.

But when $\alpha\left(r^{\prime}(B) . B+r(B)\right)>\gamma \dot{p}$, then $H_{2}(B)=\dot{B}<0$, the optimal level of debt is still decreasing, even though prices are increasing. Indeed when $\mathrm{B}(0)$ takes the value of zero and when the interest rate is exponential, this condition becomes: $\psi\left(e^{-D}-1\right)>\frac{\gamma \theta}{\alpha}-r^{*}$. This means that even in a period of relative prosperity, when the price of the natural resource is increasing, thus when the country earns more money then it used to do, the government ought to pay off its debt in priority. In the long-run, it confirms the results from the case with a debt-elastic interest rate and constant prices, which is quite similar to what was found in the benchmark model, where consumption declines. 